\title{
Impact of canopy management practices on phenolic composition and sensory profile of cv. Teran wine
}

\author{
Marijan Bubola ${ }^{1, *}$, Paolo Sivilotti ${ }^{2}$, Sara Rossi $^{1}$, Ena Bestulić ${ }^{1}$, Tomislav Plavša ${ }^{1}$, and Sanja Radeka $^{1}$ \\ ${ }^{1}$ Institute of Agriculture and Tourism, Karla Huguesa 8, 52440 Poreč, Croatia \\ ${ }^{2}$ University of Udine, Department of Agricultural, Food, Environmental and Animal Sciences, Via delle Scienze 206, 33100 Udine, \\ Italy
}

\begin{abstract}
The aim of this study was to investigate the impact of early leaf removal (ELR) and cluster thinning (CT) on the phenolic composition of cv. Teran berries and wines, and the sensory profile of wines at 6 and 24 months after fermentation. Although only ELR increased the concentration of total anthocyanins in the berries as compared to the untreated control (UC), both ELR and CT had higher concentration of total anthocyanins and greater colour intensity in the resultant wines than the UC. Similar effects were obtained with total phenolics in the berries and the wines; while CT obtained higher concentration of total phenolics in the berries than UC only in one season, same treatment obtained higher concentration of total phenolics in the wine in both seasons as compared to UC. Only minor sensory differences in wines were obtained at the age of 6 months, while treatments were highly discriminated 24 months after fermentation, when both ELR and CT wines had more enhanced fruitiness, aromatic intensity, complexity, body, balance and wine overall quality than UC. The obtained results indicate that adequate wine aging period is needed for a relevant assessment of the impact of vineyard management practices on wine sensory characteristics.
\end{abstract}

\section{Introduction}

Early leaf removal and cluster thinning are canopy management practices used to improve grape and wine quality by affecting the concentration of phenolic and aromatic compounds in grapes [1-6] Their effects are of special importance for the production of aged red wines, which are generally characterized by a high concentration of phenolic compounds that enable proper evolution of wine sensory characteristics during wine aging [7-8].

Although the impact of early leaf removal and cluster thinning practices on vine performance, berry and wine composition has been thoroughly studied in the last decades, the knowledge about their impact on wine sensory characteristics is still limited, and especially concerning the evolution of the sensory profile of the obtained wines during wine aging. Several studies report the improvement of sensory quality of wines obtained from vines subjected to early leaf removal [4, 9-10] or cluster thinning [5-6], while in some cases the effects of the treatments were mild [11-12] or were not expressed in every experimental year [2].

Chemical reactions occurring in wines during aging modify both chemical and sensory characteristics [7]. Liu et al. [13] observed that the development of aroma characteristics in wines were dependent on aging period, and 15 months bottle-aged wines showed better fragrance attributes than younger wines, despite a lower concentration of volatile compounds. The intensity of astringency and bitterness depends on the structural modification of polyphenols [8] and the same authors observed a lower intensity of astringency and bitterness, and the improvement of persistence of wine flavour with longer aging. Based on the these findings, it may be hypothesized that in case of red wines which are characterized by considerable sensory perception of tannins intensity, astringency and bitterness, the appropriate period to perform descriptive sensory analysis of wines would rather be after a certain period of wine aging (15 months or more) than on younger wines. This assumption may be especially appropriate for a Teran variety, which beside the high anthocyanin and moderate phenolic content [14] has also a pronounced acidity of grapes and the resultant wines [15]. Teran is a red grape variety traditionally grown in the north Adriatic area, including the Croatian Istria viticultural subregion [16-17].

The objectives of this study were 1) to evaluate the impact of early leaf removal and cluster thinning on basic and phenolic composition of the berries and the obtained wines and 2) to evaluate the impact of these practices on sensory characteristics of the wines at different stages of wine aging (6 and 24 months).

\section{Materials and Methods}

\footnotetext{
* Corresponding author: marijan@iptpo.hr
} 


\subsection{Vineyard site and experimental design}

The experiment was conducted in 2012 and 2013 in a commercial, non-irrigated vineyard located near Koreniki, in Croatian Istria wine growing subregion, Croatia. Teran grapevines (clone ISV-F2) grafted on Vitis berlandieri $\times$ Vitis riparia 420 A rootstock were planted in 2004 in a luvic, anthropogenized, deep Terra rossa soil, with $2 \%$ north-west oriented slope. Vines were planted with a spacing of $0.8 \mathrm{~m}$ within the row and $2.0 \mathrm{~m}$ between rows, with rows oriented north-south. Vines were trained to a vertically shoot-positioned, single-cane-pruned Guyot trellis with a bud load of about 10 nodes per vine.

Three adjacent rows were selected to build a randomized complete block design, with each row as a block. Within each row, three sections of three post spaces (21 vines per plot) were randomly assigned to the following treatments: early (pre-flowering) leaf removal (ELR), cluster thinning (CT) and non-defoliated, nonthinned control (UC). Early leaf removal was carried out before flowering (flower caps still in place, but cap colour fading from green), by manually removing from all shoots six basal primary leaves. Laterals eventually burst at the time of leaf removal were maintained. Cluster thinning was applied at the beginning of veraison (when berries begun to colour and enlarge) and approximately $35 \%$ of clusters were removed. Dates for ELR treatments were 26 May 2012 and 29 May 2013, whereas CT was performed on 31 July 2012 and 2 August 2013.

Meteorological data were recorded by a Spectrum WD 1650 weather station (Spectrum Technologies, East Plainfield, IL). Growing degree days calculated on a base temperature of $10^{\circ} \mathrm{C}$ from 1 April to 30 September were $1925^{\circ} \mathrm{C}$ and $1819^{\circ} \mathrm{C}$ in 2012 and 2013 , while total rainfall from April to September was $311 \mathrm{~mm}$ and 350 mm in 2012 and 2013, respectively.

\subsection{Microvinifications}

Microvinifications were made separately for each experimental plot. At harvest date, approximately $20 \mathrm{~kg}$ of grapes per treatment replication were de-stemmed, crushed, treated with $50 \mathrm{mg} / \mathrm{L} \mathrm{SO}_{2}$, supplied with yeast nutrient Go-Ferm Protect (Lallemand, Montreal, Canada; $0.3 \mathrm{~g} / \mathrm{L}$ ) and inoculated with Saccharomyces cerevisiae (Enoferm BDX; Lallemand, Montreal, Canada; 0.3 g/L). Three days after the beginning of fermentation $0.2 \mathrm{~g} / \mathrm{L}$ of yeast nutrient Fermaid E (Lallemand, Montreal, Canada) was added. Fermentations were conducted in $10 \mathrm{~L}$ glass fermentors at a temperature of $25^{\circ} \mathrm{C}$. Pomace was mixed two times per day. After 12 days of fermentation and maceration pomace was pressed in a pneumatic press to 1.5 Bar. Wines were racked and sulfited with $50 \mathrm{mg} / \mathrm{L}$ $\mathrm{SO}_{2}$ and stored at $15^{\circ} \mathrm{C}$.

Six months after the end of fermentation samples were taken for the chemical and descriptive sensory analyses of wines. Wines from harvest 2013 were aged further by racking and sulfiting to $30 \mathrm{mg} / \mathrm{L}$ of free $\mathrm{SO}_{2}$ each six months. A second set of samples for descriptive sensory analyses of wines was taken 24 months after the end of fermentation.

\subsection{Composition of grape juice, berries and wine}

Standard physico-chemical wine parameters were determined according to the methods of the International Organization of Vine and Wine [18]. The anthocyanin composition from the grape berry skin was determined by HPLC according to the method described by Mattivi et al. [19] and expressed as $\mathrm{mg} / \mathrm{g}$ of berry fresh weight. Total phenolic substances in berries were determined by spectrophotometer after Iland et al. [20] and expressed as $\mathrm{mg} / \mathrm{g}$ of berry fresh weight. Wine colour intensity $\left(\mathrm{OD}_{420}+\mathrm{OD}_{520}+\mathrm{OD}_{620}\right)$ and total phenol and anthocyanin concentrations in wines were determined using UV/VIS spectrophotometer (Cary 50, Varian, USA). Total phenolic compounds were quantified according to Singleton and Rossi [21], while total anthocyanins were analysed as reported by Ribérau-Gayon and Stonestreet [22].

\subsection{Quantitative descriptive sensory analysis of wines}

Quantitative descriptive sensory analysis was performed by a panel of six trained panelists, highly experienced in Teran wine sensory analysis. Wine samples stored at 16 ${ }^{\circ} \mathrm{C}$ were served at room temperature $\left(20^{\circ} \mathrm{C}\right)$. Qualitative (selection of main descriptors and vocabulary standardization) and quantitative (intensity of perception) criteria of the panelists were attuned by tasting representative samples of Teran wine through several preliminary training sessions and at the beginning of the sensory analysis. The tasters used a 10point structured scale to rate aroma or taste intensity of each descriptor $(0=$ descriptor not perceptible, $10=$ descriptor strongly perceptible).

\subsection{Statistical analysis}

One-way analysis of variance was computed using Statistica software package (version 13; StatSoft, Tulsa, OK, USA). When differences among treatments were significant, Fisher's least significant difference test at $\mathrm{p}$ $\leq 0.05$ was used to separate the means.

\section{Results and Discussion}

Leaf area and yield components data were presented in a previously published study [23]. Due to the removal of $84 \%$ of leaf area at a pre-flowering stage in a two years mean, ELR resulted with a lower berry and cluster weight, as well as $22 \%$ lower yield per vine than UC $(1.44$ and $1.85 \mathrm{~kg} /$ vine in a two years mean for ELR and UC, respectively). Early source limitation obtained by leaf removal imposes the lack of carbohydrate supply at this stage, with the consequent lower berry weight or lower percentage of berry set, resulting in lower yield per vine $[2,24]$. On the other hand, CT had $37 \%$ lower 
yield than UC as a direct consequence of the removal of clusters $(1.16 \mathrm{~kg} / \mathrm{vine}$ in a two years mean for CT). Leaf area/yield ratio was significantly increased in CT in comparison to the other two treatments, while ELR had similar value of leaf area/yield as UC due to the reduction of both leaf area and yield as compared to UC.

Berry composition data for the two years of study are presented in Table 1. Both ELR and CT had higher Brix than UC in 2013, while the higher values observed in these two treatments in 2012 were not significantly different to the UC.

Table 1. Berry composition of Teran vines subjected to early leaf removal (ELR), cluster thinning (CT) or untreated control (UC) in seasons 2012 and 2013.

\begin{tabular}{|c|c|c|c|c|}
\hline & Season & UC & ELR & CT \\
\hline $\begin{array}{c}\text { Soluble solids } \\
(\text { Brix })\end{array}$ & 2012 & 22.1 & 23.0 & 22.9 \\
\cline { 2 - 5 } & 2013 & $20.9 \mathrm{~b}^{1}$ & $22.5 \mathrm{a}$ & $22.1 \mathrm{a}$ \\
\hline \multirow{2}{*}{$\begin{array}{c}\text { Titratable } \\
\text { acidity (g/L) }\end{array}$} & 2012 & 8.2 & 8.1 & 7.7 \\
\cline { 2 - 5 } & 2013 & 8.8 & 8.9 & 8.3 \\
\hline \multirow{2}{*}{ pH } & 2012 & 3.08 & 3.13 & 3.17 \\
\cline { 2 - 5 } & 2013 & 2.98 & 2.97 & 3.03 \\
\hline \multirow{2}{*}{$\begin{array}{c}\text { Total } \\
\text { anthocyanins } \\
(\mathrm{mg} / \mathrm{g})\end{array}$} & 2012 & $1.24 \mathrm{~b}$ & $1.46 \mathrm{a}$ & $1.32 \mathrm{ab}$ \\
\cline { 2 - 5 } & 2013 & $1.66 \mathrm{~b}$ & $2.02 \mathrm{a}$ & $1.65 \mathrm{~b}$ \\
\hline $\begin{array}{c}\text { Total phenolics } \\
(\mathrm{mg} / \mathrm{g})\end{array}$ & 2012 & $2.56 \mathrm{~b}$ & $2.88 \mathrm{a}$ & $2.64 \mathrm{ab}$ \\
\cline { 2 - 5 } & 2013 & $2.85 \mathrm{c}$ & $3.57 \mathrm{a}$ & $3.12 \mathrm{~b}$ \\
\hline
\end{tabular}

${ }^{1}$ Different letters within rows indicate means separation by the Fisher's LSD test $(\mathrm{p} \leq 0.05)$.

The increase of the sugar concentration by cluster thinning is usually a consequence of a greater leaf area/yield ratio [23], while early leaf removal commonly results with better maturation and higher Brix thanks to a greater degree of younger leaves on the vine [24] and a better exposure of leaves to sunlight [10]. Titratable acidity and $\mathrm{pH}$ were not significantly affected by the investigated treatments in any year of study (Table 1). The observed high values of titratable acidity and a low $\mathrm{pH}$ at harvest is a typical characteristic of Teran variety [15]. The basic wine composition (vol \% of alcohol, titratable acidity and $\mathrm{pH}$ ) was analogous to the composition of the berry juice, although ELR and CT had significantly higher concentration of alcohol in wines than UC in both years of study (Table 2).

Interestingly, ELR obtained higher concentration of total anthocyanins than UC both in berries and in wines, while CT obtained higher concentration of total anthocyanins than UC only in obtained wines, but not in berries (Tables 1 and 2). Some other studies also reported the lack of the increase of anthocyanins in berries obtained from vines subjected to various canopy management treatments, followed by the consequent increase of the concentration of anthocyanins in the resultant wines [3,12]. We hypothesize that the observed inconsistency in the concentration of total anthocyanins in berries and wines of CT treatment are related to skin cell wall material changes occurring during ripening, as the concentration of extractable anthocyanins increase substantially in the late stages of berry ripening [25] and increased anthocyanin concentrations in wines may be obtained from grapes with more advanced fruit maturity [26]. In our study CT obtained riper fruit than UC in terms of Brix, while also titratable acidity and $\mathrm{pH}$ had a tendency towards more advanced ripening in CT $v s$. UC in both years of study.

Similar trend to total anthocyanins between grapes and wines was also observed for total phenolics; ELR increased the concentration of total phenolics in grapes and in wines as compared to UC in both years of study, while CT increased total phenolics in berries only in 2013 and increased total phenolics in wine in both years of study (Tables 1 and 2). This inconsistency which was observed for samples from 2012 is most probably linked to the ethanol concentration of wines. As reported by Sherman et al. [26], greater concentration of tannins and nontannin phenolics in wine is obtained with higher ethanol concentration, which in our study corresponded to the CT treatment as compared to UC.

Colour intensity was higher in ELR and CT than in UC in both years (Table 2), as a consequence of higher concentration of total anthocyanins in the former treatments, but also because higher ethanol concentration favours the formation of polymeric pigments leading to darker wines [26].

Table 2. Composition of wines obtained from Teran vines subjected to early leaf removal (ELR), cluster thinning (CT) or untreated control (UC) in seasons 2012 and 2013.

\begin{tabular}{|c|c|c|c|c|}
\hline & Season & UC & ELR & CT \\
\hline \multirow{2}{*}{$\begin{array}{c}\text { Alcohol (vol } \\
\%)\end{array}$} & 2012 & $12.5 \mathrm{~b}^{1}$ & $13.3 \mathrm{a}$ & $13.2 \mathrm{a}$ \\
\cline { 2 - 5 } & 2013 & $11.6 \mathrm{~b}$ & $13.0 \mathrm{a}$ & $12.8 \mathrm{a}$ \\
\hline \multirow{2}{*}{$\begin{array}{c}\text { Titratable } \\
\text { acidity (g/L) }\end{array}$} & 2012 & 7.7 & 7.8 & 7.6 \\
\cline { 2 - 5 } & 2013 & 8.6 & 8.3 & 8.1 \\
\hline \multirow{2}{*}{ pH } & 2012 & 3.16 & 3.18 & 3.19 \\
\cline { 2 - 5 } & 2013 & 3.08 & 3.13 & 3.16 \\
\hline \multirow{2}{*}{$\begin{array}{c}\text { Colour } \\
\text { intensity }\end{array}$} & 2012 & $2.05 \mathrm{~b}$ & $2.30 \mathrm{a}$ & $2.23 \mathrm{a}$ \\
\cline { 2 - 5 } $\begin{array}{c}\text { Total } \\
\text { anthocyanins } \\
\text { (mg/L) }\end{array}$ & 2013 & $2.44 \mathrm{~b}$ & $3.28 \mathrm{a}$ & $2.97 \mathrm{a}$ \\
\cline { 2 - 5 } & 2013 & $467 \mathrm{~b}$ & $449 \mathrm{a}$ & $435 \mathrm{a}$ \\
\hline \multirow{2}{*}{$\begin{array}{c}\text { Total phenolics } \\
\text { (mg/L) }\end{array}$} & 2012 & $1362 \mathrm{~b}$ & $1517 \mathrm{a}$ & $1497 \mathrm{a}$ \\
\cline { 2 - 5 } & 2013 & $1470 \mathrm{c}$ & $1914 \mathrm{a}$ & $1730 \mathrm{~b}$ \\
\hline
\end{tabular}

${ }^{1}$ Different letters within rows indicate means separation by the Fisher's LSD test $(\mathrm{p} \leq 0.05)$.

Although the wines from 2012 were not aimed and prepared for the sensorial analysis, the preliminary tasting of these wines lead to the assumption that both ELR and CT wines were of superior quality than UC, and characterized by more pronounced fruitiness, body, balance and complexity (data not shown). Following these preliminary data, wines from harvest 2013 were 
subjected to the quantitative descriptive sensory analysis six months after the end of fermentation, but also at the age of 24 months, as wine sensory characteristics may be modified due to chemical reactions during aging [7].

Only minor sensory differences were obtained among treatments in six months aged wines, while substantial differentiation in sensory characteristics among treatments occurred after the following 18 months of wine aging (Figures 1 and 2).

At six months of wine age treatments differed only in jammy and dried fruits aromas, while after a longer aging also differences in aromatic intensity and complexity, dark fruits, sour cherry, dried vegetative and aromatic herbs were observed. Most of these characteristics were more intensely pronounced in ELR and CT than in UC, although sour cherry, as a typical descriptor of Teran wines, was more intense in UC and ELR as compared to CT. In line with our findings, Liu et al. [13] observed that 15 months bottle-aged wines showed better aroma attributes than 6 to 9 months aged wines.

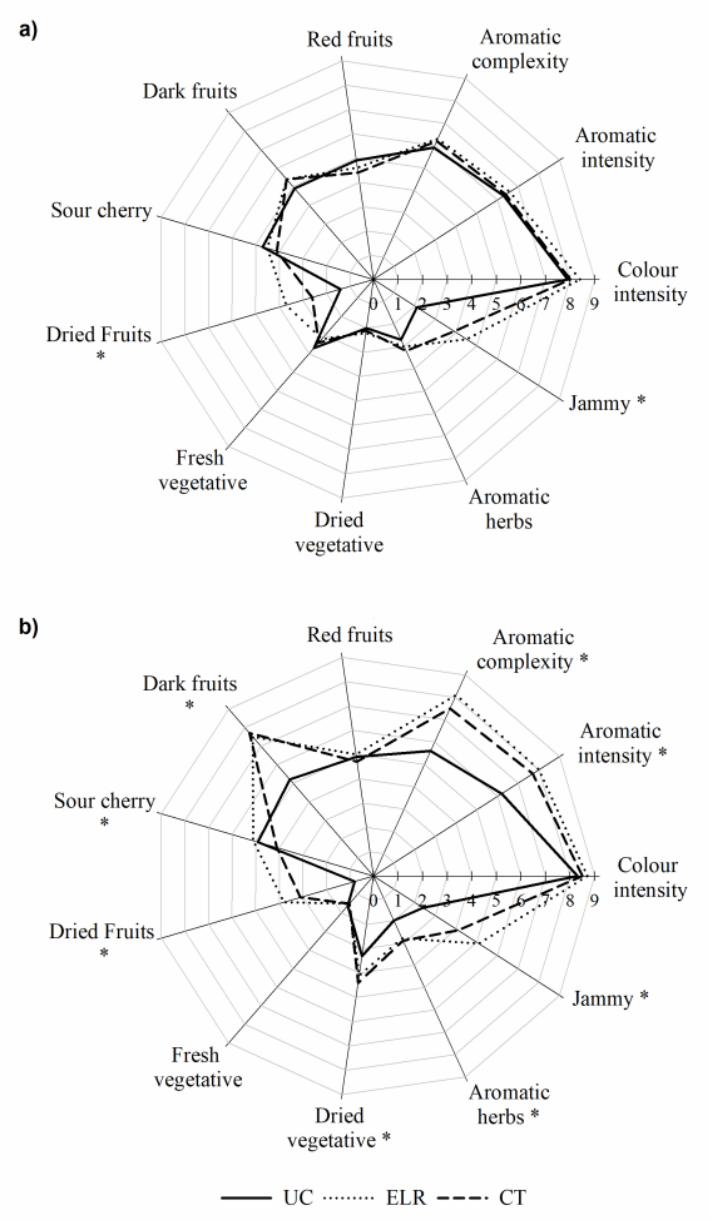

Fig. 1. Olfactory and colour characteristics of a) 6 and b) 24 months aged wines obtained from Teran vines subjected to early leaf removal (ELR), cluster thinning (CT) or untreated control (UC) in 2013. (*) Indicates means separation by the Fisher's LSD test $(\mathrm{p} \leq 0.05)$.

Concerning the taste attributes, young Teran wines at the age of six months were generally characterized by pronounced sensory perception of tannins intensity, astringency, bitterness and acidity. At this stage ELR treatment had more pronounced body, sweetness perception and taste persistence than UC and no other differences in taste were observed among wines. During red wine aging astringency and bitterness usually decrease due to structural modification of the polyphenols, while persistence of wine flavour increase [8]. Accordingly, 24 months after the end of fermentation, when the perception of astringency, bitterness and acidity in Teran wines diminished, treatments were highly discriminated in taste attributes. Both ELR and CT had more pronounced body, sweetness perception, tannins quality (defined as 'soft' tannins) and balance than UC treatment, while UC had a stronger perception of acidity than CT. Moreover, at this stage wine overall quality was higher in ELR and CT wines as compared to UC.

a)

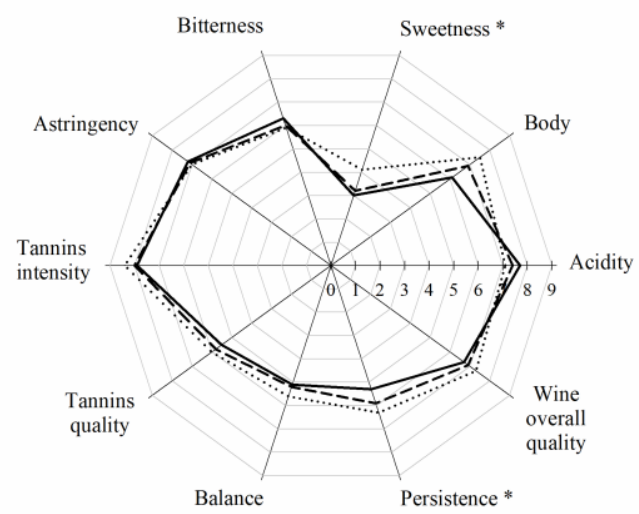

b)

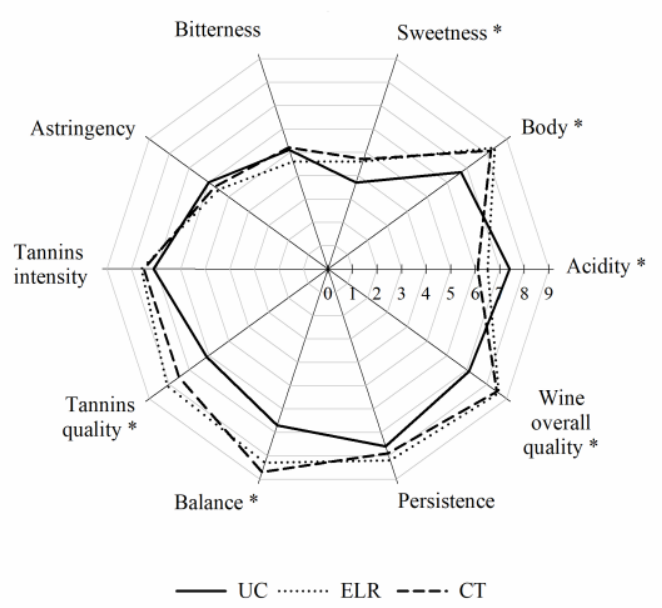

Fig. 2. Taste characteristics and overall wine quality of a) 6 and b) 24 months aged wines obtained from Teran vines from harvest 2013, subjected to early leaf removal (ELR), cluster thinning (CT) or untreated control (UC) in 2013. (*) Indicates means separation by the Fisher's LSD test $(\mathrm{p} \leq 0.05)$.

Based on the extensive differences in the effect of investigated treatments on wine sensory profile after 6 or 24 months of wine aging, it is supposed that in the studies where the early leaf removal or cluster thinning had only a mild effect on sensory quality of wines [11- 
12], or the positive effect was assessed in only one year of study [2], potentially better discrimination among treatments would be achieved if the wines were assessed after a longer aging, at a more appropriate stage of wine evolution.

\section{Conclusions}

Early leaf removal and cluster thinning are useful practices to increase the concentration of total anthocyanins and total phenolics in Teran red wine, despite the fact that little improvement in berry composition is obtained by cluster thinning. The effects of the investigated practices on wine sensory profile were modest in young wines at the age of 6 months due to pronounced sensory perception of tannins intensity, astringency, bitterness and acidity at this stage of wine evolution, while treatments were highly discriminated at 24 months of wine age, when wines of both early leaf removal and cluster thinning treatments had more enhanced fruitiness, aromatic intensity, complexity, body, balance and wine overall quality. These findings indicate that an adequate aging period is needed for a suitable assessment of the impact of vineyard management practices on red wine sensory characteristics and this assumption may be especially relevant for wines characterized with pronounced acidity, tannins intensity, astringency and bitterness, where 15 or more months may be needed to adequately evaluate the effects of the applied viticultural treatments.

\section{Acknowledgments}

This work has been partially supported by the Croatian Science Foundation under the project 'Influence of different vinification technologies on the qualitative characteristics of wines from Croatian autochthonous varieties: the role of wine in human diet' VINUM SANUM (IP-2018-01-5049).

\section{References}

1. H. Feng, P. A. Skinkis, M. C. Qian. Food Chem. 214, 736-744 (2017).

2. A. Palliotti, T. Gardi, J. Berrios, S. Civardi, S. Poni, Sci Hortic, 145, 10-16 (2012).

3. B.S. Kemp, R. Harrison, G.L. Creasy. Aust. J. Grape Wine Res. 17, 270-279 (2011).

4. T. Verdenal, V. Zufferey, A. Dienes-Nagy, G. Bourdin, K. Gindro, O. Viret, J.-L. Spring. Am. J. Enol. Vitic. 70, 427-434 (2019).

5. T.E. Rutan, M. Herbst-Johnstone, P.A. Kilmartin. J. Agric. Food Chem. 66, 10053-10066 (2018).

6. C. Condurso, F. Cincotta, G. Tripodi, A. Sparacio, D.M.L. Giglio, S. Sparla, A. Verzera. Eur. Food Res. Technol. 242, 1719-1726. (2016).

7. I. Balga, A. Leskó , M. Ladányi, M. Kállay. Czech J. Food Sci. 32, 563-569 (2014).
8. B. Sun, A.C. Neves, T.A. Fernandes, A.L. Fernandes, N. Mateus, V. De Freitas, C. Leandro, M.I. Spranger. Agric. Food Chem. 59, 6550-6557 (2011).

9. C.C. Hickey, M.T. Kwasniewski, T.K. Wolf. Am. J. Enol. Vitic. 69, 231-246 (2018).

10. M. Bubola, I. Lukić, S. Radeka, P. Sivilotti, K. Grozić, A. Vanzo, D. Bavčar, K. Lisjak. J. Sci. Food Agr. 99, 904-914 (2019).

11. M.P. Diago, M. Vilanova, J. Tardaguila. Am. J. Enol. Vitic. 61, 382-391, (2010).

12. P. Sivilotti, J.C. Herrera, K. Lisjak, H. Baša Česnik, P. Sabbatini, E. Peterlunger, S.D. Castellarin. J. Agric. Food Chem. 64, 4487-4496 (2016).

13. D. Liu, R.-R. Xing, Z. Li, D.-M. Yang, Q.-H. Pan. Eur. Food Res. Technol. 242, 1937-1948 (2016).

14. I. Lukić, S. Radeka, I. Budić-Leto, M. Bubola, U. Vrhovsek. Food Chem. 300, 125251 (2019).

15. E. Maletić et al. Green Book: Indigenous Grapevine Varieties of Croatia (State Institute for Nature Protection, Zagreb, Croatia, 2015).

16. D. Rusjan, M. Bubola, D. Janjanin, Z. Užila, S. Radeka, D. Poljuha, R. Pelengić, B. Javornik, N. Štajner. Vitis, 54(SI), 77-80 (2015).

17. M. Žulj Mihaljević, E. Maletić, D. Preiner, G. Zdunić, M. Bubola, E. Zyprian, I. Pejić. Genes, 11, 737 (2020).

18. OIV. Compendium of International Methods of Wine and Musts Analysis (Office International de la Vigne et du Vin, Paris, France, 2012).

19. F. Mattivi, R. Guzzon, U. Vrhovsek, M. Stefanini, R. Velasco. J. Agric. Food. Chem. 54, 7692-7702 (2006).

20. P. Iland, N. Bruer, G. Edwards, S. Weeks, E. Wilkes, Monitoring the Winemaking Process from Grapes to Wine (Patrick Iland Wine Promotions, Adelaide, SA, Australia 2004).

21. V. L. Singleton, J. A. Rossi. Am. J. Enol. Vitic. 16, 144-158 (1965).

22. P. Ribérau-Gayon, E. Stonestreet. B. Soc. Chim. Fr. 9, 2649-2652 (1965).

23. M. Bubola, P. Sivilotti, D. Janjanin, S. Poni. Am. J. Enol. Vitic. 68, 234-242 (2017).

24. S. Poni, L. Casalini, F. Bernizzoni, S. Civardi, C. Intrieri, Am. J. Enol. Vitic. 57, 397-407 (2006).

25. G. Allegro, A. B. Bautista-Ortín, E. Gómez-Plaza, C. Pastore, G. Valentini, I. Filippetti. Am. J. Enol. Vitic. 69, 417-421 (2018).

26. E. Sherman, D.R. Greenwood, S.G. Villas-Boâs, H. Heymann, J.F. Harbertson. Am. J. Enol. Vitic. 68, 344-356 (2017). 